\title{
DISTRRBUIÇÃO DO NERVO CUTÂNEO LATERAL DA COXA NA Área DE INUEÇ̄̃O INTRAMUSCULAR
}

\author{
Rogério Porto da Rocha*, Geraldo José Medeiros Fernandes, Alessandro Venguer, \\ Maurício leal Dias Mongon, Fábio Pizzo Ribeiro, Rodrigo Barbosa longuinho e Silva \\ Trabalho realizado no Curso de Ciências Médicas do Centro Universitário Lusíada (UNILUS), Santos, SP
}

RESUMO - A técnica de injeção intramuscular (IM) na região ântero-lateral da coxa é prática médica muito utilizada. Entretanto, apesar desta área ser apontada como segundo melhor local para esta prática, tanto em adultos como em crianças, a técnica ainda mostra-se muito dolorosa em ambos.

OвjEtIVo. Estudar a localização, distribuição, trajeto e relação topográfica do nervo cutâneo lateral da coxa com a área recomendada para prática da injeção intramuscular, relacionando-os à dor decorrente de tal procedimento.

Método. Através da exposição da região ântero-lateral por dissecção clássica, o nervo cutâneo lateral da coxa foi identificado e isolado em 20 cadáveres adultos masculinos fixados, dando-se ênfase à visualização de seus ramos nervosos sobre o tracto iliotibial.

Resultados. Após emergir medialmente em relação à espinha ilíaca ântero-superior, em 100\% dos casos, o nervo cutâneo lateral da coxa emite três ramos calibrosos em $70 \%$ dos espécimes, sendo que em $30 \%$ emite apenas dois. No terço superior, e na porção superior do terço médio da coxa, observa-se uma rede de numerosos ramúsculos nervosos envoltos por quantidade variável de tecido adiposo. Todavia, na porção inferior do terço médio da coxa e no terço inferior, não se visualizam ramos nervosos importantes.

Conclusão. Baseados em nossos dados, recomendamos a utilização da porção inferior do terço médio da coxa como local de escolha para prática de injeção IM na região ântero-lateral da coxa, por se tratar de uma região menos inervada, o que acarretará menos dor nesta área durante tal procedimento, trazendo maior conforto ao paciente.

UNITERMOS: Técnica de injeção intramuscular. Nervo cutâneo lateral da coxa.

\section{INTRODUÇÃo}

Motivados pelos dados na literatura médica e pela escassez de detalhes nas descrições anatômicas dos textos clássicos acerca do trajeto dos ramos nervosos, estudamos a localização, distribuição e trajeto do nervo cutâneo lateral da coxa e sua relação topográfica coma área recomendada para a prática da injeção intramuscular. Nosso intuito foi relacionar a dor associada à injeção intramuscular na região com a distribuição do nervo cutâneo lateral da coxa, observando cuidadosamente a inervação cutânea desta região.

A injeção intramuscular na área lateral da coxa (região do músculo vasto lateral e do tracto iliotibial) é prática médica e de enfermagem muito utilizada ${ }^{1-3}$ em adultos e crianças. Segundo textos clássicos, a técnica recomendada baseia-se no volume da massa musculare na distribuição da inervação e vascularização,

\footnotetext{
*Correspondência: Avenida Ana Costa, 118 -Vila Mathias Cep:1 1064-032-Santos-Sp-Fone: (013) 223-4579
}

\begin{tabular}{lc}
\hline & $\begin{array}{c}\text { Tabela I - Distribuição das regiões de injeção IM em relação à } \\
\text { escolha de indicação (em adulto e crianças) }\end{array}$ \\
\hline Região de injeção & Escolha de indicação \\
Ventro-Glútea & Primeira \\
Ântero-Lateral daCoxa & Segunda \\
Dorso-Glútea & Terceira \\
Deltóidea & Quarta \\
\hline
\end{tabular}

que envolvem a área lateral da coxa. Entretanto, esta técnica mostra-se muito dolorosa, principalmente emadultos.

A região ântero-lateral da coxa, em diversos textos, vem sendo apontada como o segundo melhor local de escolha indicado para a injeção IMem adultos e em crianças ${ }^{2,3}$ (Tabela I).

Textos clássicos em anatomia ${ }^{4-14}$ descrevem sucintamente o nervo cutâneo lateral da coxa, limitando-se a mostrar sua emergência do plexo lombar e na raiz da coxa. Com respeito à sua distribuição na região ânterolateral da coxa, os detalhes são omitidos ou desconhecidos.

As fibras nervosas do plexo lombar que formam o nervo cutâneo lateral da coxa são compostas por ramos das raízes $L 2$ e $L 3^{8,9}$. $O$ nervo cutâneo lateral da coxa pode-se originar do nervo femoral ou constituir um ramo independente do plexo lombar (L2, ou LI e L2) ${ }^{8}$. Sua origem extra abdominal ocorre abaixo do ligamento inguinal medialmente à origem do músculo sartório 6,9 , de onde, em seu trajeto descendente, cruza o m. sartório em sua face anterior e divide-se em dois ramos terminais: um ramo glúteo (que se dirige látero-posteriormente, cruzando o músculo tensor da fáscia lata), e um ramo femoral, que continua o trajeto vertical da emergência cutânea do nervo até a patela, ramificado-se para inervar a pele da região ântero-lateral da coxa-1! . 


\section{Métodos}

Selecionamos aleatoriamente 20 coxas (sendo 10 direitas e 10 esquerdas) de cadáveres adultos masculinos fixados, de idade entre 20 e 40 anos, todas provenientes do Laboratório de Anatomia do Curso de Ciências Médicas do UNILUS em Santos $S P$. Os espécimes apresentaram altura variando entre I,60 m e I,80 m com desvio padrão de 0,10 , e peso variando entre 60 $\mathrm{kg}$ e $90 \mathrm{~kg}$ com desvio padrão de 0, 15 .

A região da coxa escolhida para a exposição estendeu-se da região inguinal ao tendão patelar e da linha mediana anterior à margem lateral da cabeça longa do músculo bíceps da coxa.

A dissecação foi realizada da maneira clássica, por planos, procedendo-se à identificação e isolamento dos ramos nervosos subcutâneos. Deu-se especial ênfase à visualização do tracto iliotibial.

Utilizou-se o paquímetro de Vernier (MitutoyoÒDigital) para estabelecimento das medidas, sendo estas realizadas pelo mesmo observador. $O$ acompanhamento do trajeto dos ramos nervosos foi completado sob aumento (4x). Logo após, os espécimes foram fotografados para comprovar os dados encontrados.

\section{Resultados}

O nervo cutâneo lateral da coxa, em todos os casos, emerge medialmente à espinha ilíaca ântero-superior e inferiormente ao ligamento inguinal.

Em I4 espécimes (70\%), encontramos três ramos calibrosos, localizados exatamente sobre o tracto iliotibial (Figs. I e2), cujas descrições, com pequenas variações, seriam:

- O primeiro ramo, o mais vertical, calibroso e longo dos três ramos, prolongase até a porção distal do fêmur, próximo à articulação do joelho;

- O segundo ramo, com diâmetro inferior ao primeiro, dispõe-se de maneira oblíqua, formando um ângulo medial, de aproximadamente $30^{\circ}$, com o terceiro ramo;

- O terceiro ramo, mais lateral, dispõe-se com diâmetro semelhante ao segundo ramo, e segue obliquamente no sentido póstero-inferior, bifurcando-se em dois segmentos: um transversal e outro descendente.

Figura I - Origem extra-abdominal no nervo cutâneo lateral da coxa (NCL) abaixo do ligamento inguinal, em membro inferior direito, subdividindo-se em três ramos: I, 2 e 3

Figura 2 - Esquema ilustrando a distribuição do nervo cutâneo lateral da coxa (NCL) sobre a região ântero-lateral da coxa, com suas respectivas ramificações: I, 2 e 3

Em seis espécimes (30\%) encontramos dois ramos, comodescrito na literatura ${ }^{(6,10)}$, também dispostos sobre o tracto iliotibial (Fig. 3).

Nas regiões do terço superior e da porção superior do terço médio da coxa, incidindo exatamente sobre o tracto iliotibial, visualizamos uma rededenumerososramúsculosnervososenvoltos por quantidade variável de tecido adiposo(Fig.4).

Todavia, na porção do terço médio da coxa e no terço inferior, numa faixa imediatamente anterior ao tracto iliotibial, não se observa trama nervosa significativa. 
Figura 3 - Origem extra-abdominal do nervo cutâneo lateral da coxa (NCL) abaixo do ligamento inguinal, em membro inferior esquerdo, subdividindo-se em dois ramos: I e 2

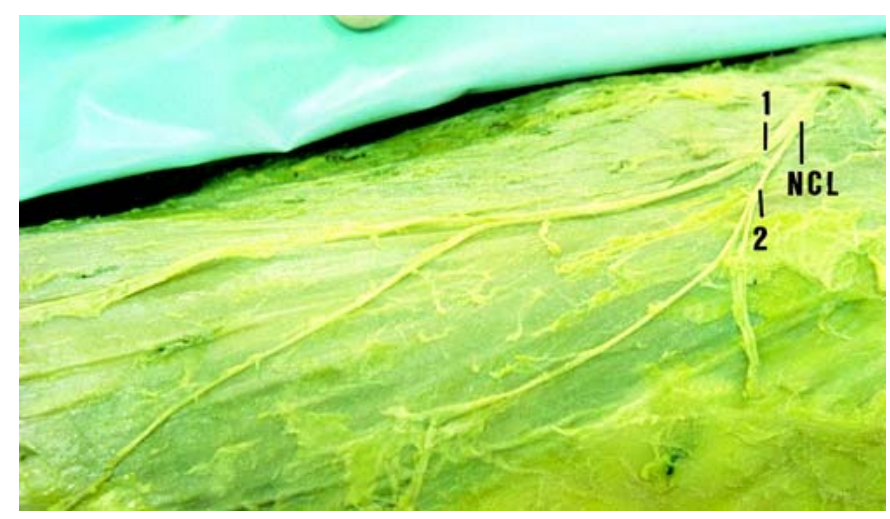

Figura 4 - Disposição do nervo cutâneo lateral da coxa ( $\mathrm{NCL})$ e de uma rede de numerosos ramúsculos nervosos (RN) envolvidos por tecido adiposo, sobre o tracto iliotibial no terço superior da região ântero-lateral da coxa

Figura 5 - Esquema ilustrando a área preconizada pela literatura para realização da injeção intramuscular na região ântero-lateral da coxa

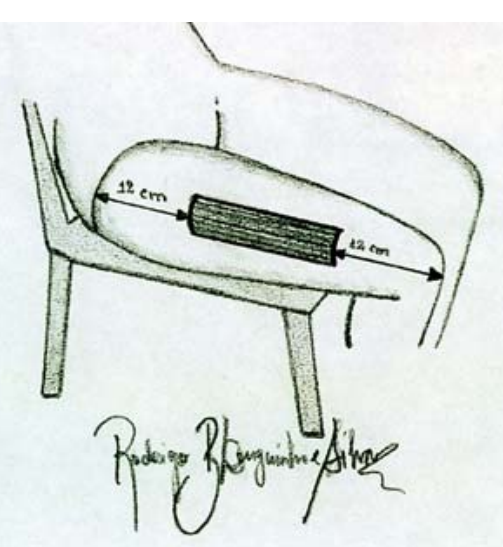

\section{Discussão}

Nossos achados diferem dos textos clássicos compilados ${ }^{6,8-10}$ porque, enquanto estes descrevem que o nervo cutâneo lateral da coxa contém dois ramos terminais (um ramo glúteo e outro femoral), o resultado de $70 \%$ de nossas dissecações revela que este nervo subdivide-se em três ramos principais.

A técnica preconizada para a injeção IMna região lateral da coxa utiliza, no adulto, uma região supostamente segura, abrangendo todo o terço médio do fêmur, anterior ao tracto

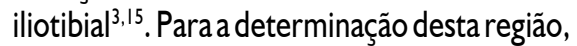
traça-se um retângulo, o qual será delimitado pelas linhas média anterior e lateral da coxa, a aproximadamente $15 \mathrm{~cm}$ abaixo do trocanter maior do fêmur, e $12 \mathrm{~cm}$ acima do joelho, numa faixa e 7 a $10 \mathrm{~cm}$ de largura(Fig. 5). Cabe ressaltar que estaárea é classicamente escolhida por não possuir estruturas anatômicas que possam ser lesadas durante o procedimento.

Segundo nossas observações, acreditamos que a porção superior do terço médio da coxa, na área preconizada pela técnica clássica, seria a região menos indicada para a aplicação de injeções intramusculares (anterior ao tracto iliotibial), pois esta apresenta intensa trama nervosa. No entanto, a porção inferior desta mesma área, também anterior ao tracto iliotibial, por não apresentar ramúsculos nervosos significantes, pode ser indicada como região de escolha para a aplicação de IM na região ântero-lateral da coxa. Trata-se, portanto, de uma área que por já estar contida dentro da área preconizada pela técnica de injeção IM clássica, não apresenta riscos de lesar estruturas importantes como vasos calibrosos, já que pelo fato de ser clássica, a técnica traz consigo a garantia de uma prática segura de injeção IM. Além de que, a própria anatomia local da porção inferior do terço médio da região ântero-lateral da coxa, observada em todas as 20 peças estudadas, nos permite confirmar a ausência de tais estruturas importantes (como vasos calibrosos), o que reforça a segurança desta técnica.

Contudo, sugerimos uma sutil, mas expressiva modificação da técnica clássica de injeção IM nesta região. Após a delimitação do retângulo, divide-se o quadrilátero em duas partes iguais, através da técnica já descrita, utilizando sua metade distal como local de escolha para realização desta injeção (Fig. 6). 
Figura 6 - Esquema ilustrando a área proposta para injeção intramuscular na região ântero-lateral da coxa, utilizando-se a metade distal do quadrilátero (área hachurada) como local de escolha para a aplicação desta injeção

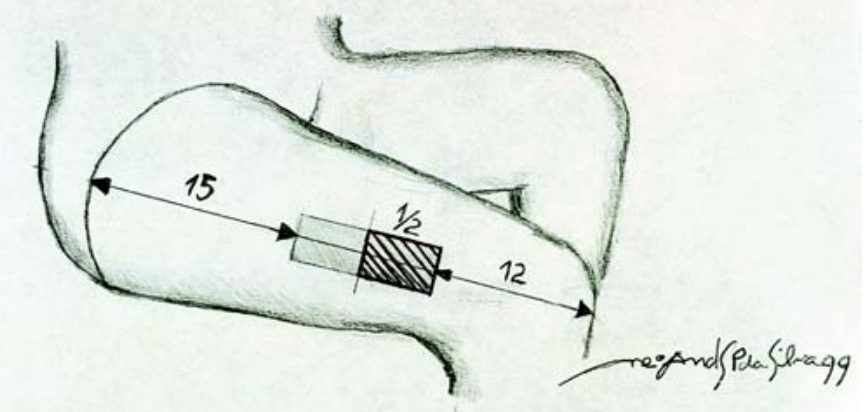

Apesar da dor local não estar relacionada exclusivamente à distribuição do NCLC sobre a região ântero-lateral da coxa, acreditamos numa diminuiç̧ão dos fatores álgicos.

Embora a dor provocada pela injeção intramuscular possa também ser devidaao comprometimento traumático de outras estruturas profundas como fásciae tendões, por exemplo, a área aqui proposta diminui a ocorrência de fenômenos dolorosos por minimizar a possibilidade de que sejam atingidos ramos nervosos.

\section{Conclusão}

Baseados nos dados obtidos da anatomia local, recomendamos considerar a utilização da porção inferior do terço médio da coxa (metade distal do retângulojá descrita na técnica clássica), como prioridade na escolha para a aplicação da injeção IM na regiãoântero-lateral da coxa sempre que possível, por se tratar de uma região com menor incidência de ramos nervosos, (região menos inervada), o que poderá acarretar menos dor nesta área durante tal procedimento, trazendo maior conforto ao paciente.

\section{SUMMARY}

Distribution OF the lateral cutaNEOUS NERVE OF THE THIGH IN THE AREA OF INTRAMUSCULAR INJECTION

The technique of intramuscular injection (IM) into the antero-lateral region of the thigh is widely used. Nevertheless, despite this area being indicated as the second best location for this practice, the technique is still observed to be very painful for both adult and child patients.

OвJECTIVE. To study the localization, distribution and course of the lateral cutaneous nerve of the thigh, and its topographic relationship with the area recommended for the practice of intramuscular injection, relating these characteristics to the pain resulting from such procedures.

METHOD. By means of exposing the anterolateral region by classical dissection, the lateral cutaneous nerve of the thigh was identified and isolated in 20 fixed adult male cadavers, giving emphasis to the viewing of its nerve rami across the iliotibial tract.

Results. In 100\% of the cases, the lateral cutaneous nerve emerged medially in relation to the upper anterior iliac spine. After this, it issued three wide-caliber rami in $70 \%$ of the specimens and only two in the remaining $30 \%$. In the upper third and in the upper portion of the middle third of the thigh, a network of numerous small nerve rami was observed, enveloped in a variable quantity of adipose tissue. However, in the lower portion of the middle third of the thigh and in the lower third, no significant nerve rami were seen.

Conclusion. Based on our data, we recommend whenever possible that the distal half of the region displayed by the classical technique be utilized as the location of choice for the practice of intramuscular injection into the antero-lateral region of the thigh. This is because this region is less innervated by the lateral cutaneous nerve of the thigh, which will cause less pain in this area during such procedures, thereby affording greater comfort to the patient. [Rev Assoc Med Bras 2002; 48(4): 353-6]

KEY WORDS: Intramuscular injection technique. Lateral cutaneous nerve of the thigh.

\section{REFERÊNCIAS}

I. Veiga DA, Crosseti MGO. Manual de técnicas de enfermagem. Porto Alegre: Sagra-DC Luzzatto; 1993. p.66-7.

2. Horta WA, Teixeira MS. Injeções parenterais. Rev Esc Enferm USP 1 973; 7:46-79.

3. Castellanos BEP. Estudo sobre as regiões para aplicação de injeções por via intramuscular. São Paulo: Ática; I 987. p.89.

4. Gray $H$, Warwick R, Williams PL, editors. Anatomia. Rio de Janeiro: Guanabara-Koogan; 1979. p.987-8.

5. Hollinshead WH, Rosse C. Anatomia. 4a ed. Rio de Janeiro: Interlivros; I99।. p.3 |4-5.

6. Rouvière $H$. Précis d'anatomie et de dissection. Paris: Masson et Cie. 1913. p.4023. (Collection de préas médicaux)

7. Chiarugi G. Instituzioni di Anatomia dell' Uomo. Milano, Societá Editrice Libreria. 1959. p. 106.

8. Gardner ED, Gray DJ, O'rahilly R. Anatomia: estudo regional do corpo humano. 2a ed. Rio de Janeiro: Guanabara Koogan; 1967. p.492.

9. Lockhart RD, Hamilton GF, Fyfe FW. Anatomia do corpo humano. 2a ed. Rio de Janeiro: Guanabara Koogan; 1983. p.270.

10. Testut $L$, Latarjet $A$. Tratado de anatomia humana. Barcelona: Salvat; 1977. p.3I5.

II. Spalteholz W. Atlas de anatomia humana. São Paulo: Roca; 1998. p.396.

12. Heidegger GW. Atlas de anatomia humana. Rio de Janeiro: Guanabara Koogan; 1974. p. 130.

13. Sobotta J, Staubesand J, ed. Atlas de anatomia humana. Rio de Janeiro: Guanabara Koogan; 1993. p.350.

14. Rohen JW, Yokochi C, Drecoll EL. Anatomia humana: atlas fotográfico de anatomia sistêmica e regional. São Paulo: Manole; 1998. p.450.

15. Becton Dickinson Indústrias Cirúrgicas. Atualização em técnicas de injeção. Arte Impressa; 1991. p.63-6.

Artigo recebido: $26 / 07 / 2001$ Aceito para publicação: 06/02/2002 